\title{
MEDELLÍN CANTADA. \\ Análisis de las canciones que refieren a esta ciudad
}

\author{
A RESOUNDING MEDELLÍN. \\ Analysis of the songs refer to this city
}

Carlos Alberto López Posada*

\section{RESUMEN}

La música popular como manifestación del sentimiento transmite en sus líricas vivencias, anhelos, el amor y el desamor, el éxito o el fracaso, la alegría o la tristeza. Estas canciones también expresan las relaciones de los seres humanos y los ecosistemas que habitan. En el artículo se presenta el análisis de las liricas con las que se nombra a Medellín, ciudad ubicada en el Departamento de AntioquiaColombia.

En los referentes líricos analizados, Medellín es orgullo de propios, vecinos y extraños; es ciudad de eterna primavera, de flores y feria. Sus mujeres, montañas, barrios, calles, avenidas, el Metro, el Metro Cable así como la "vuelta a oriente" y sus equipos de fútbol, son objeto de mención en las canciones. "Si te quieres divertir Medellín, si te quieres enamorar Medellín, dice Nelson Henríquez en "A Medellín". "Quien llega a Medellín se siente paisa, así no haya nacido aquí...", dice la canción "Ave María pues” del Grupo Galé.

En este estudio no se encuentranz canciones que aludan a sitios desagradables o peligrosos, tampoco a la ola de violencia que vivió esta localidad, denominada ahora ciudad de la esperanza.

Palabras clave: Medellín, análisis del discurso, música, canciones de Medellín, imaginarios, ciudad.

Recibido: Agosto 11, 2015 - Aceptado: Septiembre 4, 2015

\section{SUMMARY}

Popular music as an expression of the feeling conveys in his lyrics experiences, desires, love and heartbreak, success and failure, joy or sadness. These songs also express the relations of humans and the ecosystems they inhabit. In the article is presented the analysis of the lyrics with appointing Medellin, a city in the Department of Antioquia - Colombia.

In the lyrical references analyzed, Medellin is proud to own, neighbors and strangers; it is a city of eternal spring, flowers and fair. Their women, mountains, neighborhoods, streets, avenues, the Metro and Metro Cable, the "Vuelta a Oriente" and its football teams, are being mentioned in songs. "Si te quieres divertir, Medellín, si te quieres enamorar, Medellín”, says Nelson Henríquez in "A Medellín". "Quien llega a Medellín se siente paisa, así no haya nacido aquí...", says the song "Ave María pues" by Grupo Galé.

There is not allusion to unpleasant or dangerous places, nor the wave of violence experienced in this city, now called, city of hope.

Keywords: Medellin, discourse analysis, music, songs of Medellin, imaginary, city.

Received: august 11, 2014 - Accepted: september 4, 2014 
Introducción

La ciudad de Medellín cuenta con una diversidad de expresiones musicales entre las más populares la de carrilera, el tango, el bolero y la música de despecho. Otras manifestaciones musicales que tienen un espacio importante en esta ciudad es el vallenato, la salsa, el rock en español, el reggaetón [1], el metal, la música andina, entre otros géneros.

El compositor, arreglista y director de orquesta Lucho Bermúdez, oriundo de la zona caribeña de Colombia, y quien viviera en Medellín desde 1948 hasta 1963 [2], le heredó un legado musical que ha inspirado a las nuevas generaciones de músicos y orquestas como "Los Núñez" cuyo director es el maestro Abraham Núñez. Desde está orquesta se gesta un semillero infantil para que permanezca la música tropical en Medellín. Otras representantes de la música tropical son las orquestas:

La Sonora Dinamita, El Tropicombo, El Combo Dilido, Taurus Orquesta, La Tropibanda, Golden Boys, Black Star, Gustavo Quintero con Los Graduados, Los Hispanos con Rodolfo Aycardi , Gabriel Romero, Juan Piña, y El Combo de las Estrellas que se ha constituido en un ícono de la música tropical de la ciudad, entre otras.

El género de la salsa también ha tenido artistas de renombre a nivel mundial como es el caso de Fruko y sus Tesos, Latin Brothers, el Grupo Galé y el Grupo Caneo, quienes se han encargado de llevar este sabor a las "Salsa vías" y las diferentes discotecas de Medellín.

Es de recordar que los más importantes artistas de la música bailable de Colombia han grabado su música en las casas disqueras de Medellín: Codiscos, Discos Fuentes, Sonolux y Discos Victoria, entre otras. Además, en la ciudad se pueden sintonizar 8 emisoras de música tropical y salsa.

La industria de la música en Colombia tuvo su principal desarrollo en la década de 1940. Las compañías fonográficas Discos Fuentes (1934), ElectrosonoraSonolux S.A. (1949) y Codiscos (1950) dieron inicio, en el país, a una de las industrias más rentables [3].
Analizando la muestra total de las canciones que refieren a la ciudad de Medellín, se puede observar que estas expresan que es una "ciudad alegre", imaginario que aparece en el $69 \%$ de las canciones analizadas, las cuales por demás están compuestas en ritmos tropicales, hacen alusión a la fiesta, la rumba y la celebración en la ciudad.

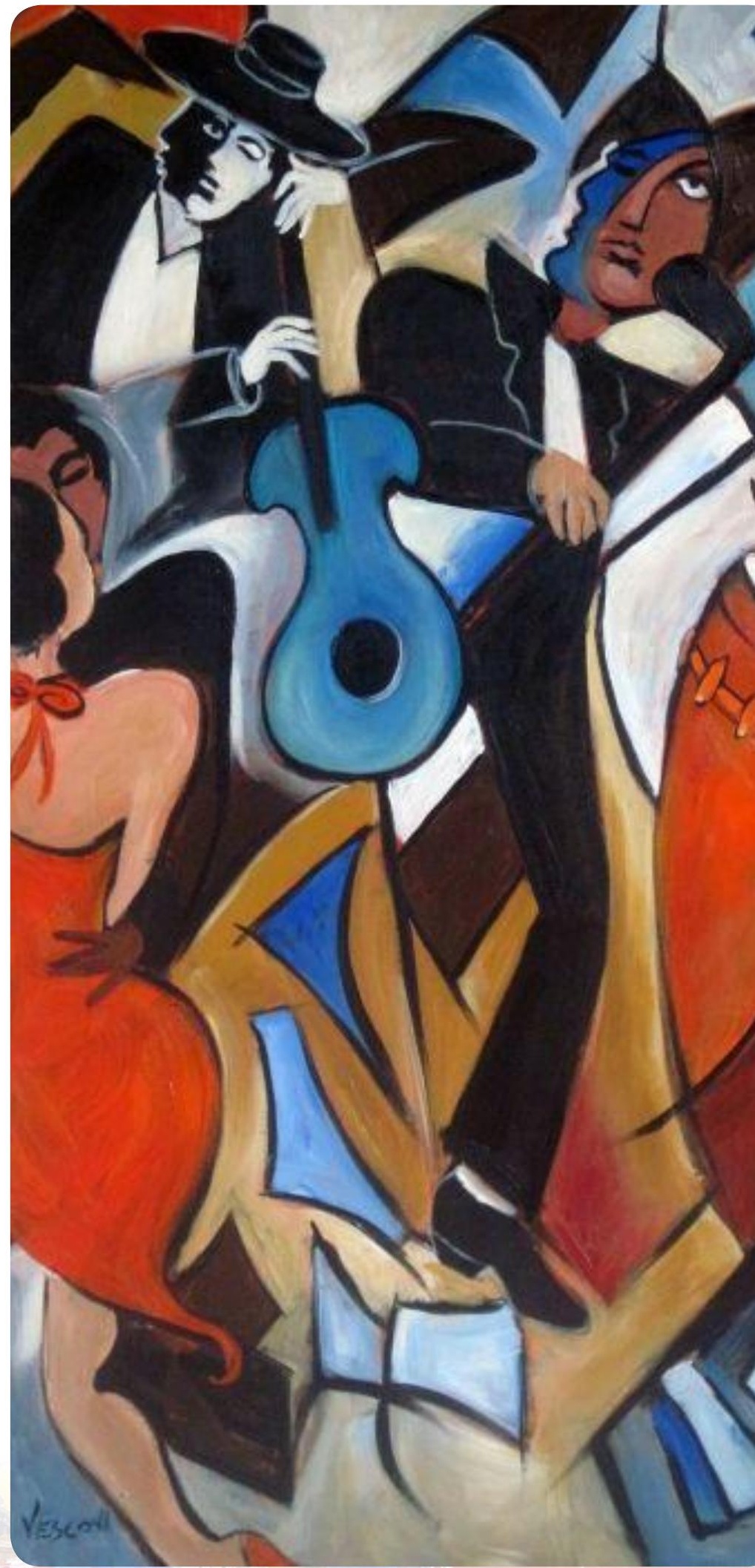


Metodología

La muestra del estudio la constituyeron 29 canciones que en sus líricas hacen mención a la ciudad de Medellín (ver tabla N1).

Tabla N1. Corpus de análisis

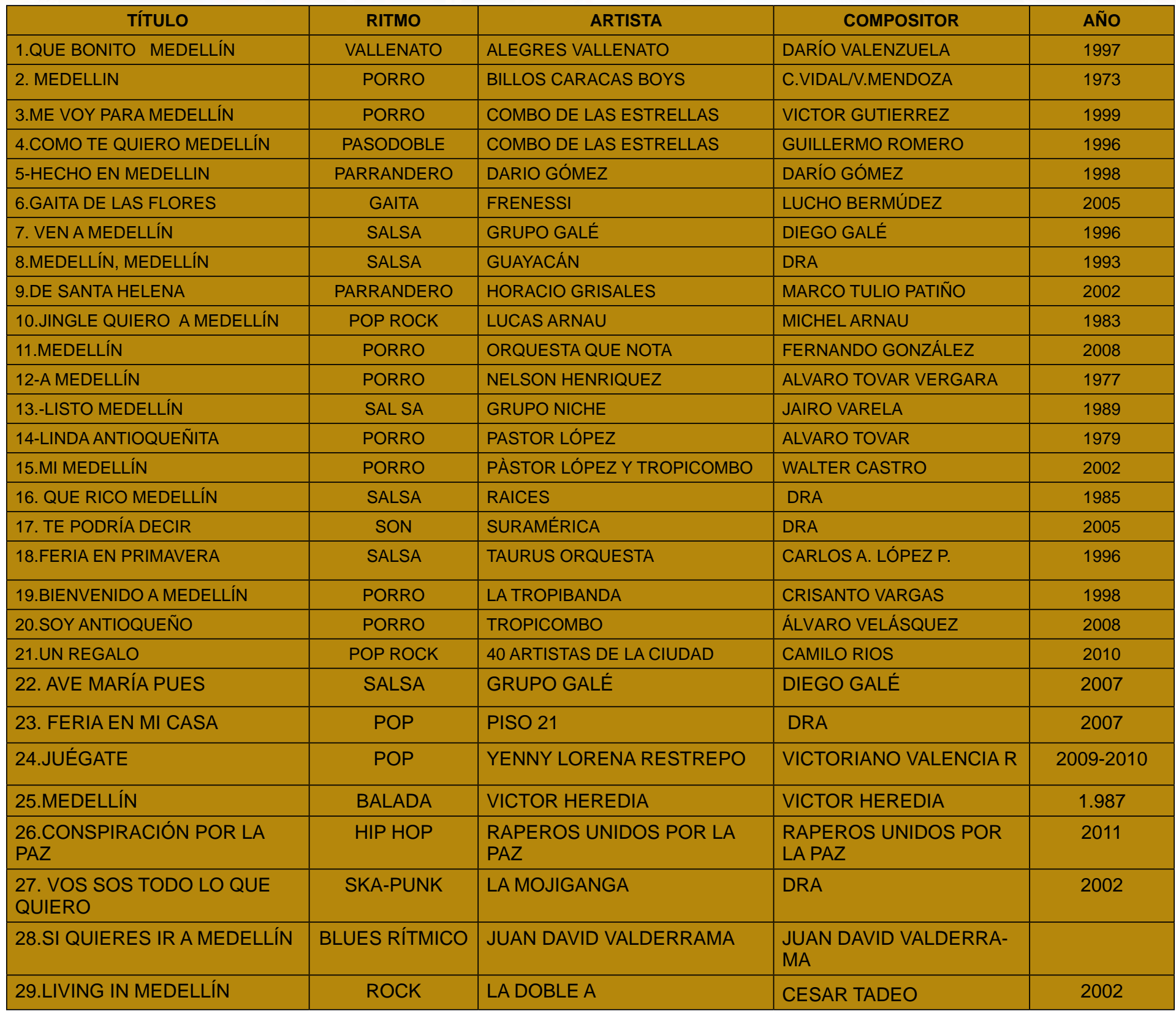

Fuente: Elaboración propia.

La metodología incluyó también la realización de ficheros para compilar información acerca de cada canción: título, autor, fecha de producción, artista que la interpreta y ritmo, así como datos acerca de sus audios, videos. Entrevistas con compositores, productores, artistas y el público; anotaciones sobre la ruta metodológica, citas, bibliografías y apuntes referentes a la investigación. 
Se realizó también una matriz de análisis, en la que además del título de la canción, y el ritmo, se sistematizó el número de veces en que se enuncian las categorías que al momento emergieron de las líricas de las canciones: Medellín, mujeres, montañas, flores, feria, mención de otros Municipios y primavera (ver tabla N2).

Tabla N2. Matriz de análisis

\begin{tabular}{|c|c|c|c|c|c|c|c|c|c|}
\hline & CANCIÓN & RITMO & MEDELLíN & MUJERES & MONTAÑAS & FLORES & FERIA & $\begin{array}{c}\text { OTROS } \\
\text { MUNICIPIOS }\end{array}$ & PRIMAVERA \\
\hline 1 & MEDELLÍN & PORRO & 15 & & & & & 2 & 1 \\
\hline 2 & A MEDELLIIN & PORRO & 11 & 2 & & & & & \\
\hline 3 & LINDA ANTIOQUEÑITA & PORRO & 3 & 2 & & & & & \\
\hline 4 & QUIERO A MEDELLIIN & POP ROCK & 5 & 1 & 1 & & & & \\
\hline 5 & QUE RICO MEDELLIIN & SALSA & 17 & & & 6 & 5 & & 1 \\
\hline 6 & MEDELLIÍN & BALADA & 2 & & & & & & 2 \\
\hline 7 & LISTO MEDELLIN & SALSA & 7 & 2 & 1 & 1 & & 4 & 2 \\
\hline 8 & MEDELLíN, MEDELLíN & SALSA & 35 & 4 & 2 & & & 2 & 2 \\
\hline 9 & VEN A MEDELLÍN & SALSA & 20 & & 2 & 1 & 1 & 1 & 1 \\
\hline 10 & FERIA EN PRIMAVERA & SALSA & 3 & 1 & & 2 & 2 & & 1 \\
\hline 11 & COMO TE QUIERO MEDELLIIN & PASODOBLE & 12 & 1 & 1 & 1 & 2 & & \\
\hline 12 & QUE BONITO ES MEDELLIN & VALLENATO & 34 & 2 & 7 & 1 & 1 & & 4 \\
\hline 13 & HECHO EN MEDELLIÍN & PARRANDERO & 5 & & & & & & \\
\hline 14 & BIENVENIDO A MEDELLIIN & PORRO & 6 & & 1 & 3 & 5 & & \\
\hline 15 & ME VOY PARA MEDELLIÍN & PORRO & 4 & 1 & & 1 & 1 & & \\
\hline 16 & DE SANTA ELENA & PARRANDERO & 4 & & & & & & \\
\hline 17 & MI MEDELLIN & PORRO & 7 & 1 & 5 & & & & \\
\hline 18 & VOS SOS TODO LO QUE QUIERO & SKA-PUNK & & & & & & & \\
\hline 19 & LIVING IN MEDELLIN & ROCK & 4 & & & & & & 1 \\
\hline 20 & TE PODRÍA DECIR & SON & 4 & & & & & & \\
\hline 21 & GAITA DE LAS FLORES & GAITA & & & & 2 & & & \\
\hline 22 & AVE MARÍA PUES & SALSA & 25 & 2 & & 2 & 3 & 6 & 2 \\
\hline 23 & FERIA EN MI CASA & POP & 1 & 1 & & 4 & 10 & 2 & \\
\hline 24 & SOY ANTIOQUEÑO & PORRO & 1 & 4 & 9 & 4 & & & 1 \\
\hline 25 & MEDELLIN & PORRO & 7 & 5 & 3 & 2 & 1 & 4 & 9 \\
\hline 26 & SI QUIERES IR A MEDELLIN & BLUES RITMICO & 9 & & & & & & \\
\hline 27 & UN REGALO & POP ROCK & 3 & & & & & & \\
\hline 28 & JUEGATE & POP & 5 & & & & & & \\
\hline 29 & CONSPIRACIÓN POR LA PAZ & HIP HOP & 3 & & & & & & 1 \\
\hline & TOTAL & & 252 & 29 & 32 & 30 & 31 & 21 & 28 \\
\hline
\end{tabular}

Fuente: Elaboración propia.

La matriz anterior se depura en otra en la que toman las categorías emergentes de ciudad, ciudadanos y otredades para el análisis. 
Tabla 3. Matriz de categorías

\begin{tabular}{|c|c|c|c|c|c|}
\hline CODIGO & CANCIÓN & CIUDAD & CIUDADANOS & OTREDADES & $\begin{array}{l}\text { NACIONALIDAD DE } \\
\text { LOS INTERPRETES }\end{array}$ \\
\hline \multirow{3}{*}{1} & \multirow{3}{*}{ MEDELLÍN } & M edellín se divisa desde las colinas & Cochice Campeón M undial & Envigado & \multirow{3}{*}{ Venezuela } \\
\hline & & Cuna de hombres forjadores & & Itagüi & \\
\hline & & $\begin{array}{l}\text { Los laur eles, La A merica, Guay aquil, } \\
\text { Manrique. El cerro Nutibara.Parque de }\end{array}$ & & & \\
\hline \multirow{5}{*}{2} & \multirow{5}{*}{ A M EDELLÍN } & \multirow{5}{*}{ Paraíso terrenal } & Mujeres bellas & & \multirow{5}{*}{ Venezuela } \\
\hline & & & Paisa seré & & \\
\hline & & & Soy muy feliz lo juro por Dios & & \\
\hline & & & Me siento en mi casa & & \\
\hline & & & Gente cordial & & \\
\hline \multirow{4}{*}{3} & \multirow{4}{*}{ LINDA ANTIOQUEÑITA } & Ciudad Divina & Medellín te canto & \multirow{4}{*}{ Porteño } & \multirow{4}{*}{ Venezuela } \\
\hline & & Cuna de mujeres tan divinas & Porque yo te quiero & & \\
\hline & & Donde estan las reinas & Yo siempre te llevo & & \\
\hline & & & En mi pensamiento & & \\
\hline \multirow{5}{*}{4} & \multirow{5}{*}{ QUIERO A MEDEயIN } & Lugar donde nací & Caras alegre & & \multirow{5}{*}{ Antioqueño } \\
\hline & & Con mis amigos creci & niños felices & & \\
\hline & & La ciudad para mis hijos & Lindas mujeres & & \\
\hline & & $\begin{array}{c}\text { En sus Barrios, sus montañas y en sus } \\
\text { parques y en sus calles siempre está el } \\
\text { amor }\end{array}$ & hombres honestos & & \\
\hline & & Donde vivo y trabajo & & & \\
\hline \multirow{4}{*}{5} & & De Junín a Maracaibo & $\begin{array}{c}\text { Las paisitas caminando coqueteando } \\
\text { las veras }\end{array}$ & & \\
\hline & QUE RICO MEDELLÍN & Eterna primavera & El antioqueño es un caballer 0 & & Barranquilla \\
\hline & & Cordial y sincera & & & \\
\hline & & Hay que rico es Medellín & & & \\
\hline & & Ciudad colombiana & Gamines, esos niños marginales & & \\
\hline 6 & MEDELLÍN & Un pueblito "paisa" & & $\begin{array}{l}\text { sueños } \\
\text { s. }\end{array}$ & Argentina \\
\hline & & Ciudad bonita & tratando de quedarse con algo mío & & \\
\hline & & Medellin eterna primavera & Mujeres rosas que adornan el jardín & Estoy de Cali llamando & \\
\hline & & De la montaña la reina plena & del Valle de Aburrá & En Nueva York esperando & \\
\hline & & Yo en la playa paseando & & A Bello a Copacabana & \\
\hline & & En Junín estoy pensando & & Pa' Envigado y pa' Itagüí & \\
\hline 7 & LISTO M EDELLIN & Campo Valdés se va alegrar & & & Cali \\
\hline & & $\mathrm{Pa}^{\prime}$ Villa hermosa pa' guayabal & & & \\
\hline & & Barrio Antioquia la Castellana & & & \\
\hline & & Aranjuez y San Javier & & & \\
\hline & & A la Floresta me voy de fiesta & & & \\
\hline & & Para M anrique en general & & & \\
\hline & & Capital de la montaña & Mujeres lindas & Visitar Itagüí & \\
\hline & & \begin{tabular}{|c|} 
Visitar el pueblito paisa la playa la oriental \\
Junín
\end{tabular} & Gente gentil & $\begin{array}{l}\text { Si se sube a M onserrate mi hermano } \\
\text { esta en Boootá }\end{array}$ & \\
\hline 8 & MEDELLIN, MEDELLIN & & Quiero vivir ahora en Medellín & $\begin{array}{c}\text { Si pasea por la quinta avenida usted } \\
\text { está en NY }\end{array}$ & Cali \\
\hline & & & & Torre Eiffel usted está en parís & \\
\hline & & Medellín brillante lucero & Raza linda y sin igual pura casta & & \\
\hline & & $\begin{array}{c}\text { Hay mi bella ciudad donde expreso todo el } \\
\text { sentimiento }\end{array}$ & & & \\
\hline 9 & VENA MEDELÚN & $\begin{array}{l}\text { Medellín tierra donde todos somos como } \\
\text { hermanos }\end{array}$ & & & M edellin \\
\hline & & Medellín flor de primavera & & & \\
\hline & & Valle de aburra capital de la montaña & & & \\
\hline & & Su nombre llego al mundo entero & & & \\
\hline & & Medellín es una flor & $\begin{array}{c}\text { Sus gentes lindas, cordiales muestran } \\
\text { la raza y el tesón }\end{array}$ & & \\
\hline 10 & FERIA EN PRIMAVERA & $\begin{array}{c}\text { Es la ciudad más hermosa, que imaginó el } \\
\text { creado }\end{array}$ & $\begin{array}{c}\text { Sus hombres bravos y fuertes } \\
\text { enseñan todo elvalor }\end{array}$ & & Evigado \\
\hline & & \begin{tabular}{|c|} 
Que rico Medellín para gozar \\
\end{tabular} & & & \\
\hline & & De la Playa a la Setenta & & & \\
\hline 11 & COMO TE OUIERO MEDE L IN & $\begin{array}{c}\text { Medellín de mis amores con olor a } \\
\text { maroarita }\end{array}$ & & & Medellìn \\
\hline 11 & COMO IE QUIERO MEDEUIN & $\begin{array}{c}\text { Medellín como te adoro Por ser ejemplo } \\
\text { nacional }\end{array}$ & & & The enerimit \\
\hline & & La ciudad de la eterna primave & Sus mujeres y su gente tan gentil & & \\
\hline 12 & QUE BONITO ES M EDELLIN & La ciudad más alegre y parrandera & & & M edellin \\
\hline & & Medellín la capital de la montaña & & & \\
\hline 13 & HECHO EN MEDELLIIN & & & & M edellin \\
\hline & & Capital de la montaña & Gente está feliz y muy dispuesta & & \\
\hline 14 & BIENVENIDO A MEDELLIIN & Mi ciudad es como un jardín & Los silleteros de Santa Elena & & M edellin \\
\hline & & Nutibara fiel testigo de esta ciudad & Artesanos dibujando bellas figuras & & \\
\hline & & Tierra tan hermosa & Mujeres como diosas & & \\
\hline 15 & ME VOY PARA MEDELÚN & La del Cerró Nutibara & Silleteros & & Medellin \\
\hline & & Cuna de los Ahurra & & & The enenimi \\
\hline & & Pueblo amante y soberano & & & \\
\hline
\end{tabular}




\begin{tabular}{|c|c|c|c|c|c|}
\hline CODIGO & CANCIÓN & CIUDAD & CIUDADANOS & OTREDADES & $\begin{array}{l}\text { NACIONALIDAD DE } \\
\text { LOS INTERPRETES }\end{array}$ \\
\hline \multirow{3}{*}{16} & \multirow{3}{*}{ DE SANTA ELENA } & Junín & Montañeros & & \multirow{3}{*}{ Medellin } \\
\hline & & Maturín & & & \\
\hline & & Santa Elena & & & \\
\hline \multirow{7}{*}{17} & \multirow{7}{*}{ MI MEDELLIN } & Nido de montañas & Bellas mujeres & & \multirow{7}{*}{ Venezuela y Medellín } \\
\hline & & Jardin de amor & $\begin{array}{l}\text { Con su cordialidad siempre te } \\
\text { enamora }\end{array}$ & & \\
\hline & & Valle de aburra & & & \\
\hline & & Tierra de pioneros & & & \\
\hline & & Cuna de los arrieros & & & \\
\hline & & Tierra de la paz & & & \\
\hline & & Tacita de plata & & & \\
\hline 18 & \begin{tabular}{|l|} 
VOS SOS TODO LO QUE QUIERO \\
\end{tabular} & & & & \\
\hline 19 & LIVNG IN MEDELLIN & La 80 & Seresviolentos & & \\
\hline \multirow{3}{*}{20} & \multirow{3}{*}{ TEPODRIADECIR } & La playa & Hembra muy fina & \multirow[t]{3}{*}{ El oriente es parte de nuestro espacio } & \multirow{3}{*}{ Medellín } \\
\hline & & Te hace muy feliz & Gente buena & & \\
\hline & & & Campesino de ancestros & & \\
\hline 21 & GAITA DELAS FLORES & & & & Medellin \\
\hline \multirow{13}{*}{22} & \multirow{13}{*}{ AVE MARIA PUES } & Parque Lleras & Silleteros & Envigado & \multirow{13}{*}{ Medellin } \\
\hline & & El Poblado & Muy paisa & Sabaneta & \\
\hline & & La 33 & Mujeres bellas que adornan mi jardin & Caldas & \\
\hline & & Pueblito Paisa & & LaEstrella & \\
\hline & & La playa con Junín & & Itagüí & \\
\hline & & La 70 & & & \\
\hline & & Manrique, Villa Hermosa, La Milagrosa & & & \\
\hline & & El San ador & & & \\
\hline & & Santa Elena & & & \\
\hline & & Plaza de Botero & & & \\
\hline & & Los pies descalzos & & & \\
\hline & & Parque de Berrio & & & \\
\hline & & Valle de Aburra & & & \\
\hline \multirow{3}{*}{23} & \multirow{3}{*}{ FERIA EN MI CASA } & Tierra de poncho, collar de arepas & Silletero & Bello & \multirow{3}{*}{ Medellín } \\
\hline & & Pueblo hermoso & Mujeres bellas & Sabaneta & \\
\hline & & Valle lleno de flores & & & \\
\hline \multirow{6}{*}{24} & \multirow{6}{*}{ SOY ANTIOQUEÑO } & Tierra linda & Mujeres bellas & & \multirow{6}{*}{ Medellín } \\
\hline & & Tierra bendita & Gente linda, activa y pujante & & \\
\hline & & Montañas majestuosas & Buena y orgullosa & & \\
\hline & & Madre amorosa & Juanes orgullo paisa & & \\
\hline & & Tierra más amable y generosa & & & \\
\hline & & Paraíso de las flores & & & \\
\hline & & Cerro Nutibara & Mujeres flores hermosas & Lavuelta oriente & \\
\hline & & El Parque Berrio & Jardín de diosas & El peñol & \\
\hline & & Eterna primavera & Rosas divinas & Envigado & \\
\hline 25 & MEDELLIN & El cerro y el rio & $\begin{array}{l}\text { Mujeres que muy llena de nobleza } \\
\text { están }\end{array}$ & La Estrella & Medellín \\
\hline & & La gardeliana & Belleza incomparable & Sabaneta & \\
\hline & & Ciudad Botero & Juanes & Itagüi & \\
\hline & & La playa con Junín & René Higuita & & \\
\hline & & Guayaquil & Gordas las flacas y bellas & & \\
\hline 26 & SI QUIERES IR A MEDELLIN & Estación Cisneros & Montañeros & & Medellín \\
\hline & & Parque botero & Gente feliz & & \\
\hline 27 & UN REGALO & Mi hogar & & & Medellín \\
\hline & G & Mi jardín & & & \\
\hline 28 & JUEGATE & & & & \\
\hline & & Mi paraíso & & & \\
\hline 29 & CONSPIRACIÓN POR LA PAZ & Esquinas violentas & & & Medellin \\
\hline & & Comuna 13 Territorio de arte & & & \\
\hline
\end{tabular}

Fuente: Elaboración propia. 
El umbral es el porcentaje mínimo de apariciones de una palabra dentro de la muestra seleccionada: cuando el umbral es mayor al $60 \%$, se dice que es un imaginario; cuando es mayor al $80 \%$, se dice que es un emblema y cuando es mayor al $90 \%$, se dice que es un croquis (Silva, 1987).

En las líricas en las que se menciona a la ciudad de Medellín se alude a que: Medellín es una ciudad alegre, es orgullo de sus ciudadanos, es una ciudad de mujeres bellas, es una ciudad orgullosa de sus montañas, es la ciudad de las flores, es eterna primavera. Medellín es La Feria de Flores y esta es Medellín. Medellín es añoranza, cariño y gratitud. Los vecinos de esta ciudad se sienten parte de ella. Me voy para Medellín es la canción más representativa de la ciudad.

\section{Los hallazgos}

\subsection{Medellín es alegría}

"Un emblema se define como una representación social de alta concentración simbólica desde un punto de vista urbano o por todo un conjunto ciudadano" (Silva, 2004). Es como un ícono de las manifestaciones culturales que se convierte en representante de una ciudad y permite evocarla. En las canciones analizadas podemos inferir que la ciudad es alegre por la forma como están escritas sus líricas:

Pastor López le canta a Medellín: "Este porrito sabroso que quiero cantarle yo...", (canción "Linda Antioqueñita").Se refiere al porro tapao en un estilo muy paisa, diferente al porro costeño. Este es un ritmo que se baila mucho en las fiestas de la ciudad. "Si se quiere divertir, Medellín...”, “...si se quiere ser feliz Medellín, si se quiere gozar más, Medellín..." (Canción "A Medellín”, N. Henríquez). Este verso es una invitación a encontrar la felicidad en Medellín por medio de sus fiestas y su Feria con sus tablados en los que actúan orquestas y agrupaciones de música tropical.

En el jingle "Quiero a Medellín” (L. Arnau), se refleja la alegría de la ciudad en esta frase: “...caras alegres bajo la luna, niños felices cerca del sol...”. En este verso se involucra a la población infantil como elemento esencial de la sociedad; si los niños reflejan alegría, es un buen indicador de la actitud de los habitantes de la ciudad.
El Grupo Raíces de Cali, recrea en la canción "Que rico Medellín", toda la fiesta que se vive en la ciudad: "Hay que rico es Medellín, se goza de noche, se goza de día...", “... rico, rico, rico....". Esta es una expresión muy popular que manifiesta el buen ambiente que reina en la ciudad. Cuando la gente la está pasando bien, manifiesta que está pasando "rico".

"Feria en Primavera" es una canción de Taurus Orquesta, que además del término "rico" agrega el "chévere" que alude a bueno.

\begin{abstract}
"...chévere, que rico Medellín para gozar; chévere, que rico ya la feria va a empezar. Metro a metro rumbea Medallo con sabor $y$ felicidad, pues la fiesta ha comenzado y los paisas vamos a gozar, gozar..."
\end{abstract}

\subsection{Medellín: orgullo de sus ciudadanos}

La palabra Medellín se menciona 252 veces en las 29 canciones seleccionadas, lo que hace pensar que es una palabra que potencia el sentido de pertenencia por la ciudad desde el imaginario urbano de sus habitantes. "Quien llega a Medellín se siente paisa, así no haya nacido aquí...", dice la canción "Ave María pues" del Grupo Galé.

Ser paisa es una condición que enorgullece a los Antioqueños, particularmente a los medellinenses; paisa es una palabra apócope de paisano. El paisa se caracteriza por ser una persona amable, generosa, respetuosa, trabajadora, emprendedora, religiosa y costumbrista; que ama profundamente a su tierra. "Ave maría pues", es una expresión que le identifica.

Esta misma canción dice:"...orgullosamente allí nací...", “...que a mí me entierren en Medellín...", "...porque sin mi tierra no puedo vivir, soy muy paisa y muero así...".

De igual forma la canción “De feria en Medellín” afirma: "...todo el que llegue a mi tierra por primera vez ya se quiere quedar...". No solo sus habitantes se sienten orgullosos de su ciudad, también los extranjeros que la visitan. Alberto Style de Puerto Rico, rima así en la misma canción: “...yo recuerdo cuando iba viajando de puertorro a Medellín, - puertorro es Puerto Ricobajando por las palmas el paisaje que yo vi no se compara; que belleza, que tierra hermosa por eso dicen que el que llega a esta tierra se enamora, por eso vivo en Medellín, quien te lo dice es Alberto Style". 
El paisaje de Medellín es incomparable, en este se conjugan el verde de la vegetación y sus montañas, con el azul del cielo. Para los extranjeros es muy atractivo el clima primaveral de la ciudad, una expresión popular entre ellos: "el peligro de Medellín es que no te quieras volver a ir".

Lucas Arnau recrea en el Jingle "Quiero a Medellín", el siguiente mensaje: "El lugar donde nací y con mis amigos crecí la ciudad para mis hijos, donde vivo y trabajo por ti. Medellín crece contigo, su progreso es para todos, depende también de ti, darle amor a Medellín..." termina esta canción con la frase: “...quiero a Medellín”.

La canción "Ven a Medellín" del Grupo Galé define de una manera explícita, su admiración por la ciudad: "Medellín brillante lucero, su nombre llegó al mundo entero...", y continua adulando: "...jay! mi bella ciudad donde expreso todo el sentimiento...", "...eres la primera lo puedo decir, mi Medellín...", “...Medellín qué hermosa tu eres...", "Medellín si lejos me encuentro mi corazón necio se quiere salir...". La canción no ahorra en calificativos para vivir en la ciudad, lo que podemos ratificar con el siguiente verso: "...me quedo en Medallo..."-como popularmente se le dice a Medellín- “...ven a Medellín, ven a Medellín verás que nunca te quieres ir...", "...que será que tienes tú que el que llega aquí se amaña; mi linda Medellín como te quiero a ti...", y termina redundando: "...que yo me quedo, yo me quedo, me quedo en Medallo...".

\subsection{Medellín: ciudad de mujeres bellas}

Las mujeres son un emblema de Medellín; la palabra mujer está presente 29 veces en las canciones alusivas a la ciudad. En el imaginario están presentes como seres muy valiosos e importantes que representan la belleza de una raza, que se precia de tener las mujeres más lindas del país. No en vano, la ciudad ostenta el título de 6 reinas, 6 virreinas y 11 princesas en la historia del Concurso Nacional de la Belleza de Colombia.

Pero no solo la belleza es física, las canciones denotan una belleza femenina del alma: “...lindas mujeres que son ejemplo..." (Jingle "Quiero a Medellín”, L. Arnau). Medellín es considerada una tierra paradisiaca: “...paraíso terrenal mujeres bellas, gente cordial..."
(Canción "A Medellín", N. Henríquez) considerada "...cuna de mujeres tan divinas como el mar y como el cielo...", "...tu eres Medellín, donde están las reinas" (Canción "Linda Antioqueñita", P. López).

La canción "¡Qué rico Medellín!" del grupo Raíces destaca en su letra: "...por la calle encontrarás las paisistas caminando, coqueteando las verás..." "... Antioqueña, antioqueñita por ti daría las flores más hermosas del alma mía..." "Paisitas" se les dice a las mujeres de Medellín, quienes engalanan la ciudad con su caminado elegante y sus miradas coquetas que enamoran a los hombres que las admiran.

\section{Jairo Varela compositor de "Listo Medellín" escribe de las mujeres medellinenses: "...son tus mujeres rosas que adornan el jardín del Valle de Aburra...".}

Guayacán Orquesta canta: "...con mujeres tan hermosas, tan lindas como unas rosas que engalanan con su aroma y olor al Valle de Aburrá...". La letra de "Feria en Primavera" de Taurus Orquesta exalta el valor de las mujeres: "...sus mujeres, orgullo de la nación...". El tema "Qué bonito es Medellín" de los "Alegres Vallenato", se refiere a la gentileza de sus mujeres.

El compositor Víctor Gutiérrez recrea en la letra de "Me voy para Medellín”, una bella analogía: “...de mujeres como diosas...". Walter Castro compositor de "Mi Medellín”, menciona en la canción: “...a tus bellas mujeres cortejan los luceros...".

\subsection{Medellín: una ciudad orgullosa de sus montañas}

Medellín está ubicada en el Valle del Aburrá, lugar rodeado de montañas. En las canciones analizadas se menciona la palabra montaña como un elemento que embellece la ciudad y del cual sus habitantes se sienten muy orgullosos. La orquesta Billos Caracas Boys define la topografía de la ciudad así: "Desde las colinas de Medellín, se divisa el Valle del Aburrá..."

En el jingle "Quiero a Medellín se canta : “...en sus barrios, sus montañas y en sus parques $y$ en sus calles siempre está el amor...”. El Grupo Niche en la canción "Listo Medellín", dice: “...de la montaña la reina plena...”. 
Guayacán Orquesta, define a la ciudad como: “... capital de la montaña...". La canción "Qué bonito es Medellín" de los Alegres Vallenatos, complementa con la frase: "...y las montañas adornando a Medellín...”. Crisanto Vargas en la canción "Bienvenido a Medellín" dice: “...la capital de la montaña está de fiesta...”.

El Combo de las Estrellas canta: “...como te adoro mi Medellín, Medellín con tus montañas...". Walter Castro en "Mi Medellín" exclama: “...mi nido de montañas...", y termina diciendo: “...sin tus montañas muero...".

Álvaro Velásquez en la canción "Soy Antioqueño", dice: "...de la montaña vengo, de la montaña soy...", “...en esta tierra bendita puso Dios todas las rosas, las montañas majestuosas...".

El Combo Qué Nota, también se refiere a las montañas

“...porque sus canto, sus montañas...”, “...su clima, sus montañas como las quiero...”.

La mayoría de los medellinenses tienen raíces que los atan a los pueblos montañeros de Antioquia, cuya migración a la ciudad se dio por el desarrollo socioeconómico, de su capital Medellín.

\subsection{Medellín: la ciudad de las flores}

La palabra "flores" se nombra 30 veces en las canciones analizadas, como un ícono de parte de la economía regional y nacional, pero a la vez como un elemento que enaltece la belleza de la naturaleza de la ciudad. No en vano se cultivan flores de manera importante en dos de sus corregimientos: Santa Elena y San Cristóbal y en sus alrededores, en el oriente cercano.

Taurus Orquesta destaca en la canción "Feria en Primavera", la importancia de las flores para la ciudad: "...Es la ciudad más hermosa que imagino el creador, con sus flores...."

En Medellín las flores permiten dibujar las ilusiones de los paisas en un río humano acompañado de silletas en la Feria de las Flores.

La canción "Gaita de las Flores" del maestro Lucho Bermúdez, está pensada para ser cantada y bailada en esta fiesta magna de los medellinenses. El grupo musical Piso 21 en la canción "Feria en mi casa", expresa: ..si tú supieras lo que yo siento al ver su valle lleno de flores...". Las flores asoman los sentimientos más profundos de los habitantes, ante la belleza de sus colores y sus inigualables aromas.

El Tropicombo canta: "...tierra de las flores y de mujeres bellas...", "...Medellín de mis amores de mujeres tan bellas paraíso de las flores...".

\subsection{Medellín es La Feria de las Flores y esta es Medellín}

En las canciones seleccionadas se menciona 31 veces la palabra feria. Esta aparece como imaginario urbano. No en vano, hace parte de la agenda pública de la ciudad. Este evento se realiza desde hace 54 años.

El Grupo Raíces describe la alegría que se derrocha en este evento: "...se goza de noche, se goza de día, feria de las flores y la simpatía...". La Feria de las Flores es una fiesta que involucra toda clase de eventos públicos y privados, para todos los gustos; estos se presentan desde las primeras horas de la mañana, para culminar con los tablados populares en las últimas de la noche.

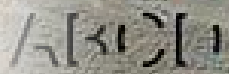

El Grupo Galé invita a conocer la ciudad y disfrutar su feria: "...ven a Medellín, la Feria de las Flores tú la disfrutarás de paso...". Taurus Orquesta anuncia la feria como el gran acontecimiento de los paisas: "Se vino pues, se vino pues, lo que los paisas querían; se vino pues, se vino pues Feria de las Flores y la alegría...", “...chévere, que rico ya la feria va a empezar...". Desde el mes de junio inicia la campaña de expectativa para la Feria que se lleva a cabo en los primeros días del mes de agosto. La radio y la publicidad en vallas, anuncian el evento cumbre del año para la ciudad. 
2.7 Medellín: ciudad de la eterna prímavera

En el imaginario de los habitantes de Medellín está la primavera como estación climática predominante en la ciudad. La palabra primavera aparece 28 veces en las canciones. Si cruzamos esta información con otras variables encontradas en las letras de las canciones, podemos determinar que la alegría de los habitantes de Medellín está marcada por el clima primaveral que predomina en la ciudad.

La Billos Caracas Boys canta: "...siguiendo al poblado tu sentirás la primavera eterna de Medellín...". El Poblado es uno de los barrios más emblemáticos, no por ser popular, sino porque se constituyó como el ícono del poder donde habitan las personas con más alto poder adquisitivo de la ciudad.

El Grupo Raíces expresa: “...yo te quiero Medellín por tu eterna primavera...". Víctor Heredia, cantautor argentino, reconoce en la ciudad el privilegio de su clima, dice: "...regálame en primavera, tu eterno canto de amor...", "...como una bella corona de eterna primavera...".

Dentro de la clasificación de música tropical, la palabra "primavera" toma la connotación de imaginario urbano, porque en el $60 \%$ de las canciones muestreadas se menciona esta palabra. La temperatura, el follaje de las plantas y árboles, la luz del sol y las matas permanentemente florecidas, ratifican por qué la ciudad recibe el apelativo: "la ciudad de la eterna primavera".

\subsection{Otredades de añoranza, cariño y gratitud}

Curiosamente muchos artistas de otras ciudades e incluso de otros países le cantan a la ciudad de Medellín con un sentimiento profundo, como si fueran de esta ciudad. Como una manifestación de la admiración y el cariño, Nelson Henríquez de Venezuela canta:

"Qué tiene esa tierra, toda esa gente de Medellín, que tiene esa bella que tiene ahí la dulce canción; yo no sé que pasa pero lo cierto es que cuando voy, me siento en mi casa soy muy feliz lo juro por Dios..."; continúa diciendo: “...paraíso terrenal..."; y termina la canción: "Me voy pa' allá, paisa seré en Medellín me quedaré...".
Pastor López de Venezuela le dice: "Medellín ciudad divina..." y continúa elogiándola: "...te canto porque yo te quiero, yo siempre te llevo en mi pensamiento...". López desarrolló parte de su carrera artística en Medellín. En la canción "Que rico Medellín", el grupo Raíces de la ciudad de Cali asegura: " ...en esta tierra cualquiera se amaña..."

El Grupo Niche de Cali evoca “...Medellín, Medellín, Medellín, (listo); yo no te puedo, no te puedo dejar, (listo); yo no te quiero, no te puedo olvidar...", "... del jardín la flor primera, (listo); de la montaña la reina plena...".

Víctor Heredia de Argentina escribió "...amo esta ciudad colombiana...". Alberto Style de Puerto Rico, dice "...el que llega a esta tierra se enamora por eso vivo en Medellín..." La canción "Feria en Primavera" de Taurus Orquesta, enaltece con su lírica la belleza de la ciudad, en los siguientes versos: “...Medellín es una flor, llena de encanto y belleza...", y continúa derrochando adjetivos: "...es la ciudad más hermosa que imaginó el creador..."

Los habitantes de Envigado y el área metropolitana, se sienten como habitantes de la ciudad de Medellín, borrando las fronteras geográficas del imaginario ciudadano. "Si el mapa marca unas fronteras determinadas de propiedades políticas y geográficas, los croquis desmarcan los mapas y los hacen vivir su revés: no lo que se impone (como frontera)" (Silva, 1987).

Darío Valenzuela del municipio de Sabaneta expresa sus sentimientos de admiración a esta ciudad, "iAy! qué lindo y bonito es Medellín...", "Ay que lindo y sabroso es Medellín...." "...por todo eso la queremos con amor...", "...Medellín ay Medellín donde todo el que llega se amaña...".

Los versos de Pastor López de Venezuela es una dedicatoria a la ciudad y sus virtudes:

\footnotetext{
"Mi Medellín del alma Dios bendiga tu suelo...", "...hoy te quiero dedicar...un tributo sincero...", “...tienes la grandeza celestial...", "...broche de oro con que Dios cerró su creación...". “...Medallo lindo carajo...", “... eres la esperanza de un país...”, “...mi tacita de plata...", “...gracia inmensa que pudo existir. y al nacer se llamó Medellín...”, “.. el paisa te quiere a ti, el paisa te adora...".
} 
2.8.1 Los vecinos de Medellín se sienten como de esta ciudad

Los municipios vecinos a Medellín, se mencionan

21 veces en las canciones, como si hicieran parte de la ciudad, borrando las fronteras geográficas al integrarlos en las actividades cotidianas de los habitantes.

La orquesta Billos Caracas Boys de Venezuela devela otredades que si bien no refieren directamente a Medellín, la ayudan a engalanar. “...si vas a Itagüí tu disfrutarás, si quieres comer a Envigado vas...".

Jairo Varela del Grupo Niche en la canción "Listo Medellín", integra los barrios de esta ciudad con sus municipios vecinos, "... .listo, para Manrique en general listo, Campo Valdés se va a alegrar listo, pa' Villa Hermosa, pa' Guayabal listo, todo el conjunto quiere bailar listo, y listo, barrio Antioquia, La Castellana listo, Aranjuez y San Javier listo, a La Floresta me voy de fiesta listo, pa' Envigado y pa' Itagüí...". Pasar de los barrios de Medellín a los municipios vecinos es muy fácil porque las distancias son muy cortas.

Guayacán Orquesta, le canta a las calles más importantes del Centro de la ciudad: "La Playa, La Oriental, Junín..."

Diego Galé mezcla de nuevo la actividad de los barrios de la ciudad, "... a un paso está El Poblado, -barrio de Medellín-, Envigado, Sabaneta-municipios aledaños-, la rumba completa si regreso del sur yo me encuentro Caldas, La Estrella, Itagüí..."municipios vecinos-.

El grupo Piso 21 asume los municipios del área metropolitana, como si hicieran parte de Medellín: “...pa' los tablados de la ciudad y desde Bello hasta Sabaneta...".Fernando González también mezcla los equipos de fútbol de la ciudad con el del Municipio de Envigado: "...orgullo de mi pueblo Envigado, Medellín y Nacional..." de igual forma une el paseo dentro de la ciudad con los municipios vecinos, como si estuvieran dentro de la misma: "...paseando con mi gente: por La Playa con Junín, La Estrella, Sabaneta e Itagüí...".
En las canciones analizadas se encuentran escenarios de fiesta y rumba en la ciudad, se hace mención a:

Calles y avenidas: La Oriental, San Juan, Junín, Maturín, La Playa y Maracaibo, la 70 la 33, la diez. Barrios: Laureles, Guayaquil, Manrique, Campo Valdés, Villa Hermosa, Barrio Antioquia, La Castellana, Aranjuez, San Javier y El Popular. Lugares: el Estadio, el Parque Lleras, el Cerro Nutibara, Parque de Berrio, el Paseo de Las Palmas, el Pueblito Paisa, Santa Elena.

Otros referentes mencionados en las canciones son el Metro, el Metro Cable y la vuelta a oriente. "Diríamos que son símbolos (en el sentido peirciano) en tanto espacios de representación (Silva, 2004)". En las canciones analizadas no se mencionan sitos peligrosos de la ciudad.

\section{Conclusiones}

En las líricas en las que se menciona a la ciudad de Medellín se alude a la alegría, al orgullo de ser de esta ciudad, a sus mujeres bellas, a una ciudad orgullosa de sus montañas, a la Feria de las Flores y a su clima primaveral. En estas canciones hasta los habitantes de otros municipios son de Medellín; se alude también al cariño y a la gratitud de los medellinenses. Me voy para Medellín es la canción más representativa de esta ciudad.

De las 29 canciones de la muestra, en el $93 \%$ de sus líricas se menciona la palabra Medellín. Por lo que se puede inferir que la palabra se presenta como un emblema. En varias de las canciones se manifiesta que se quieren morir en esta ciudad.

Dentro de las 20 canciones muestreadas de género tropical el $60 \%$ mencionan la palabra "mujeres", con lo que puede indicar que las mujeres son un imaginario urbano.

Aunque la palabra montaña no está en el umbral, se podría determinar que "es una representación social de alta concentración simbólica” (Silva, 2004). Las montañas actúan como íconos de la cultura urbana de los paisas. La palabra "flores" se nombra 30 veces en las canciones analizadas. Esta palabra, actúa como un imaginario urbano, debido a que el $65 \%$ de las canciones que hablan de Medellín involucran en sus líricas, dicha palabra. 
La Feria de la Flores es un emblema urbano porque activa la evocación de la ciudad en el imaginario de sus habitantes de una manera positiva. Mediante ese sentimiento los ciudadanos anhelan volver a su ciudad a celebrar uno de los eventos de su cultura. La palabra "eterna primavera" actúa como un ícono de la cultura paisa que representa a esta urbe al interior y exterior del país. "...los emblemas pueden convertirse en estandartes ciudadanos para un determinado territorio" (Silva, 2000).

\section{Bibliografía}

ADORNO, Theodor W. (1964). "La industria cultural". Communications3. Madrid.

-------- (1984). Crítica cultural y sociedad. Madrid: Sarpe.

(2004). Teoría estética. Madrid: Akal.

ARTEAGA, José; SILVA, Armando y otros. (1993). Los Imaginarios y La Cultura Popular. Bogotà: Cerec.

AUGÉ, Marc. (2000). Los no lugares espacios del anonimato. Barcelona: Gedisa S.A.

BARBERO, Jesús Martín. (1993). Industria cultural: capitalismo y legitimación. Ediciones simbióticas

BELL, P. T., (1921) Colombia: A Commercial and Industrial Handbook, Government Printing Office, Washington

BENJAMIN, Walter. (1973-1989). "La obra de arte en la época de su reproductibilidad técnica". Discursos interrumpidos. Madrid: Taurus.

BERRY, A. (1987) "The Limited Role of Rural SmallScale Manufacturing for LateComers: Some Hypotheses on the Colombian Experience", Journal of Latin American Studies, pp.295-332.

BOTERO, Nora. (2011). "Cibernautas y la Medellín imaginada: entre el ethos y el thanatos". Trabajo de investigación para optar al título de magister en comunicación educativa. Universidad Tecnológica de Pereira-Universidad de Medellín

BUSTAMANTE, Enrique. Tremblay, Gaetan y otros. (2011). Industrias creativas. Amenazas sobre la cultura digital. Barcelona: Gedisa S.A.

CASTELLS, Manuel. (2000). La ciudad de la nueva economía. Conferencia pronunciada en el Salón de ciento del ayuntamiento de Barcelona.

ECHAVARRÍA, J. J., (1999) Crisis e Industrialización. Las Lecciones de los Treintas, TM Editores, Banco de la
República, Fedesarrollo, Bogotá

ECO, Umberto. (2004). Apocalípticos e integrados. Barcelona: Ediciones 62.

GARCÍA, Canclini, Néstor. (1996). Industrias culturales y globalización. Caracas: Nueva Sociedad.

HAGEN, E. E., (1971) "The Transition in Colombia”, P. Kilby, Entrepreneurship and Economic Development, The Free Press, pp.191-224.

HORKHEIMER, Max y Theodor W. Adorno. (1994). Dialéctica de la llustración. Madrid: Trotta

JAY, Martin. (1.984). Adorno. Madrid: Siglo XXI.

LINDÓN, Alicia. (2007). ¿Qué son los imaginarios y cómo actúan en la ciudad? En:- Revista Eure. (\#99, pp. 89-99). Santiago de Chile

LIPOVETSKY, G y J. Serroy. (2009). La pantalla global. Cultura mediática y cine en la era hipermoderna. Barcelona: Anagrama.

LIPOVETSKY, G y J. Serroy. (2010). La cultura-mundo. Respuestas a una sociedad desorientada. Barcelona: Anagrama.

MAYA FRANCO, Claudia María. Adorno y la industria cultural: de la Escuela de Frankfurt al internet. En: Nexus. Revista de comunicación social. $N^{\circ} 7$, Junio de 2010. ISSN 1900-9909.

MAYOR, A. (1989) Historia de la Industria Colombiana 1930 - 1968. Enciclopedia Nueva Historia de Colombia. Planeta. Bogotá. ISBN 958-614-258-2

MENKE, Christoph. (1997). La soberanía del arte: la experiencia estética según Adorno y Derrida. Madrid: Visor.

PÉREZ, Camilo \& Agudelo, Cristina. (2009). Altavista: un caleidoscopio. Medellín: Resolución digital S.A.

PINTOS, Juan. Silva, Armando y otros. (2006). Proyectar Imaginarios. Bogotá: leco.

SILVA, Armando. (2004). Imaginarios urbanos: hacia la construcción de un urbanismo ciudadano. Metodología / Armando Silva. Bogotá: Convenio Andrés Bello. Universidad Nacional de Colombia.

------- . (2006). Imaginarios Urbanos. Bogotá: Arango Editores.

TAYLOR, Charles. (2006). Imaginarios sociales modernos Barcelona: Paidós Ibérica.

ZAMORA, José Antonio. (2004). Theodor W. Adorno: pensar contra la barbarie. Madrid: Trotta. 
[1] El reggaetón es una tendencia fuerte en la ciudad, lo que la ha convertido en la meca desde donde este género se expande por Colombia con más de 300 grupos conformados.

[2] La orquesta de Lucho Bermúdez fue la atracción principal del Hotel Nutibara, el Club Campestre. Lucho Bermúdez fue también director artístico musical de la emisora La Voz de Antioquia.

[3] Discos Fuentes fue fundada por Antonio Fuentes en 1934 en la ciudad de Cartagena; Industria Electrosonora Sonolux S.A. por Antonio Botero Peláez en la ciudad de Medellín en 1949 y Codiscos instituida en 1950 por Alfredo Diez Montoya.

\section{Para citar este artículo:}

LÓPEZ Posada, Carlos (2015). MEDELLíN CANTADA. Análisis de las canciones que refieren a esta ciudad. Revista Luciérnaga/Comunicación, Año 7, N13. Facultad de Comunicación AudiovisualPolitécnico Colombiano Jaime Isaza CadavidPCJIC \& Facultad de Ciencias de la Comunicación - Universidad Autónoma de San Luis Potosí- UASLP. México. ISSN 2027- 1557. Págs. 42-54. 